\title{
DISCURSOS NA CONSTRUÇÃO DE INIMIGOS: A GUERRA ÀS DROGAS COMO OBJETO DE INTERVENCIONISMO E REPRESSÃO DE GRUPOS SOCIAIS.
}

Leone Henrique Rodrigues Santana ${ }^{1}$

Resumo: Este artigo busca explorar o processo de securitização da guerra às drogas desempenhado pelos Estados Unidos, partindo dos esforços iniciais, quando o tema ainda não era politizado, até o momento em que passou a ser securitizado, ganhando assim um caráter de maior importância e atenção por parte dos Estados. Foi buscado a partir daí identificar tanto alguns dos agentes causadores, quanto algumas das consequências advindas deste processo de securitização, passando de um nível individual, através da forma do ser, até um nível coletivo, que lida com políticas que deixam de afetar um só local para afetar todo um sistema. Para isso, foi feita uma análise de artigos que tratam sobre tema, assim como de discursos e esforços empregados por líderes políticos que possuíam entre seus grandes propósitos a guerra às drogas. Desta forma, foi possível refletir que dentre os objetivos estavam não só o combate a estas substâncias agora ilícitas, mas também a certos grupos sociais e étnicos, observando-se assim a introjeção da cultura do medo sobre a sociedade, as influências sobre o pensamento individual e coletivo e como a guerra às drogas podem e vêm sendo utilizadas de modo a afetar ainda mais alguns grupos historicamente reprimidos.

Palavras-chave: Securitização, Sociedade, Racismo, Guerra às Drogas, Higienização.

\footnotetext{
${ }^{1}$ Graduando em Relações Internacionais pela Pontifícia Universidade Católica do Rio de Janeiro (PUCRio) 


\section{Introdução}

Causa ou consequência? Embora este seja um tema recente, a chamada "Guerra às Drogas" é responsável por grande influência em diversos setores da sociedade, inclusive no âmbito social e econômico. Sua construção é pautada em um discurso onde as drogas são postas como causa de inúmeros problemas; entretanto, o que se observa é que todo o aparato construído em torno desta questão, ainda que seja tido como mera consequência para o combate das drogas, também possui significativa parcela de culpa, se apresentando também como causa de alguns dos problemas enfrentados hoje em nossa sociedade.

Em todo o transcurso responsável por construir o que hoje conhecemos como "guerra às drogas", é imprescindível que se reconheça a importância dos discursos e informações que, gradualmente se encarregaram por naturalizar sobre a sociedade a ideia de que todo este combate não só é benéfico, mas também necessário. Em poucas décadas, foi possível observar a construção de um aparato burocrático, com leis proibitivas que se expandiram por todo o mundo, muita das vezes sem qualquer questionamento mais profundo acerca do que realmente estava em jogo.

A "guerra às drogas" pode ser entendida como a securitização do problema do narcotráfico por parte dos Estados Unidos, ator responsável por delimitar e convencer que a questão se trata de uma ameaça existencial, já que o problema que o país enfrentava com as drogas nas décadas de 1970 e 1980 era atribuído à causa de outros diversos problemas sociais internos, como um aumento da violência.

Toda esta guerra, entretanto, é responsável por gerar um aumento da criminalização, da insegurança e, porque não, da violência que era tida como causa exclusiva das drogas e agora passa a ser vista também como consequência de todo o aparato político criado pelo Estado norte-americano com o objetivo de combater o problema.

No presente artigo, buscou-se fazer uma análise sobre o processo de securitização da Guerra às Drogas por parte dos Estados Unidos, assim como a internacionalização deste problema. Além disso, busco apresentar como a Guerra às Drogas vem sendo utilizada como instrumento de influência dos EUA em países da América Latina, a partir da exportação de todo um aparato burocrático e da construção de políticas que se fazem presentes além do território norte-americano no âmbito econômico, social e militar.

CSOnline - Revista Eletrônica de Ciências Sociais, Juiz de Fora, n. 25 (2017), pp. 1-296. 
A pesquisa ainda passa pelas posturas adotadas por presidentes norte-americanos no combate às drogas e também sua inserção num contexto histórico. A premissa deste trabalho é retratar os efeitos negativos advindos da securitização de um tema que teve como uma de suas principais consequências o intervencionismo. Este se apresenta tanto na produção de insegurança a determinados grupos sociais e étnicos, em uma intervenção direta ao ser, quanto também através de políticas externas que visam, entre outros, a manutenção do status-quo dos Estados Unidos através de uma maior influência econômica e política ao redor do mundo.

\section{Da repressão à (macro)securitização}

A guerra às drogas é um tema historicamente recente; há cerca de cem anos não existia qualquer estatuto de caráter proibitivo sobre estas substâncias, atualmente tidas como ilícitas. Cem anos atrás, não existia o que hoje conhecemos por narcotráfico, faz-se importante então uma análise do histórico que envolve esta questão para uma maior compreensão acerca dos problemas que acometem e são também acometidos por esta questão, em uma busca por ponderar acerca da grandeza que este tema assume hoje em nossas vidas cotidianas.

Em 1912, na Conferência de Haia, também conhecida como "Convenção do Ópio" foi estabelecido um primeiro tratado que, apesar de não proibir a produção, venda e consumo de qualquer substância, foi responsável por estabelecer uma intervenção sobre esta questão que até então não era regulamentada. Com uma atenção especial ao Ópio e seus derivados, a Conferência buscava limitar a utilização da substância às chamadas finalidades médicas, já pré-estabelecendo então a diferença entre o que hoje conhecemos como uso recreativo e uso medicinal.

Sete anos mais tarde, em 1919, nos Estados Unidos, foi estabelecida a chamada Lei Seca, sendo esta a primeira vitória dos partidários de repressão às drogas e às pessoas associadas a elas (RODRIGUES, 2012). A Lei Seca foi uma emenda à constituição estadunidense que tornava ilegal a produção, comercialização e o consumo de álcool no país. Esta proibição foi não somente ineficaz em diversos pontos, mas também uma grande falha responsável por inúmeras consequências negativas sobre a sociedade norteamericana. (THORNTON, 1991).

Embora tenha sido revogada alguns anos mais tarde, em 1933, faz-se importante uma observação acerca desta lei, suas falhas e consequências, para que seja possível estabelecer um reconhecimento de dois importantes legados. O primeiro a ser destacado é o fortalecimento de grupos ilegais que se dedicaram na época ao tráfico de álcool. 
Segundo empresários da época, durante a proibição, havia cerca de dez vezes mais lugares que se podia encontrar álcool, se comparado ao período anterior à emenda constitucional (THORNTON, 1991). Outra importante herança estendida mais adiante foi o modelo proibicionista que, mesmo tendo sido reconhecidamente falho, foi estendido para outros psicoativos. (PROVINE, 2007 apud RODRIGUES, 2012)

No plano internacional, a questão só começou a receber uma legislação de caráter proibitivo, de fato, na Convenção de Genebra, ocorrida em 26 de junho de $1936^{2}$. Nesta conferência se estabeleceu um acordo entre os Estados lá presentes que visava penalizar com prisão ou outras penas privativas de liberdade a fabricação e comercialização de diversos tipos de drogas.

Entretanto, a simples proibição aqui apresentada não condiz com todo o aparato de combate às drogas que atualmente existe ao redor do mundo e faz com que Estados destinem milhões de seu orçamento em busca de combater uma suposta ameaça. Todo este aparato hoje existente não advém somente de conferências ou legislações proibitivas, mas também de um processo de securitização que começou a ser desempenhado a partir das décadas de 1960 e 1970, que transformava a questão e a elevava para um outro nível não só de atenção internacional, mas também de mecanismos para combate.

A ideia de um tema representar uma ameaça à segurança nacional é um importante fator no processo de securitização e na consequente mudança de postura para o tratamento do tema. Como discutido na Escola de Copenhague (BUZAN, WAEVER, WILDE, 1998), há uma diferença entre um assunto ser politizado ou securitizado. Quando politizado, entende-se que o assunto faz parte da política pública do Estado e requer alguma forma de governança, já quando securitizado, a questão é apresentada como uma ameaça existencial e exige políticas fora dos limites normais.

A apresentação das drogas como sendo uma ameaça existencial, representa o ponto de alternância da questão que deixa de ser politizada e passa a ser securitizada, ou seja, deixa de ser tratada através de políticas normais e passa a ser tratada através de políticas especiais. Essa transgressão das drogas para um tema que representa uma ameaça existencial ao Estado e sua população, todavia, não poderia ser construída por qualquer ator. $\mathrm{O}$ processo de securitização de uma questão ocorre a partir de um ato de fala. Entretanto, o simples ato de fala não é o suficiente para securitizar uma questão; é necessário que o ator responsável por invocar a securitização detenha grande poder e

\footnotetext{
${ }^{2}$ Decreto n. 2.994 de 17 de agosto de 1938 responsável por ratificar o acordo firmado em Genebra em 1936.

Disponível em: http://www.oas.org/juridico/MLA/pt/bra/pt_bra_1936_convencao_repressao_trafico.pdf CSOnline - Revista Eletrônica de Ciências Sociais, Juiz de Fora, n. 25 (2017), pp. 1-296.
} 
capacidade no cenário internacional para convencer toda uma plateia da necessidade daquele ato de securitização (Buzan et. al, 1998). Sendo assim, a questão não necessariamente precisa representar uma ameaça real, o que realmente importa é a capacidade de convencimento daquele ator interessado na questão.

Neste caso, ninguém melhor que os Estados Unidos, hegemonia detentora de grande capital social, para desempenhar este papel não só de criminalização, mas da securitização do tema e a consequente construção de uma verdadeira guerra às drogas; se antes, há cerca de cem anos, o assunto mal era socialmente politizado, agora ele passa a ser alvo de grande atenção não somente do Estado, mas também da população e de diversos setores da sociedade.

Entre os marcos que tange o aumento da repressão das drogas, está o governo de Richard Nixon (1969-1974), responsável por estabelecer que as drogas eram o "principal inimigo" do país. Em discurso na Casa Branca ${ }^{3}$ no ano de 1971, Nixon justificou as medidas repressivas que viriam a ser tomadas dali em diante ao anunciar que "o inimigo público número um dos Estados Unidos é o abuso de drogas. Para lutar e derrotar este inimigo, é necessário empreender uma nova e completa ofensiva" (NIXON, 1971).

Como já discutido por Campbell (1992), este processo de reconhecimento das drogas como sendo uma ameaça e um perigo ao Estado, porém, é sobretudo uma questão de interpretação. Ou seja, apesar de já haver discussões sobre o tema antes das décadas de 1960 e 1970, a chamada guerra às drogas veio a ter seu início efetivo quando os Estados Unidos, a partir de próprios interesses internos e externos, a serem discutidos mais enfaticamente adiante, passaram a fazer e exportar uma análise das drogas como sendo uma ameaça ao Estado, imputando-as assim, através de um efeito de interpretação, como sendo uma ameaça real (CAMPBELL, 1992).

Quando se securitiza um tema, não se define somente quem deve ser protegido, mas também quem deve ser vitimado para que a ameaça seja eliminada. Segundo análise de Bigo, para a securitização, se faz necessário a insegurança de outrem; logo, a segurança de um leva a insegurança de outro, em uma interdependência de ambos os conceitos (BIGO, 2008). Ao decretar que os Estados Unidos deveriam ser protegidos da ameaça que as drogas representavam para o Estado, também foi definida a vítima desta ação; as consequências se refletem em um processo de (in)securitização que possui grande influência sobre determinados grupos étnicos e sociais, a serem discutidos mais adiante.

\footnotetext{
${ }^{3}$ Discurso responsável por estabelecer um programa de intensificação sobre o controle de drogas, realizado em 17 de junho de 1971 por Richard Nixon.

Disponível em: http://www.presidency.ucsb.edu/ws/?pid=3047

CSOnline - Revista Eletrônica de Ciências Sociais, Juiz de Fora, n. 25 (2017), pp. 1-296.
} 
Importante questão também para a ocorrência da securitização da guerra às drogas foi, entre outras, o fim da Guerra Fria. Ambos se relacionam a partir do momento em que, durante o período de conflito, se havia estabelecido uma interpretação comum de que a União Soviética e o Comunismo representavam uma ameaça existencial para os Estados Unidos e o mundo.

Com o declínio da guerra, se fazia necessário o estabelecimento de uma nova ameaça existencial para se pautar não só a identidade norte-americana, mas também as políticas que seriam tomadas dali em diante; o fim da Guerra Fria e o início da guerra às drogas representou uma mudança no foco para que fosse mantida a mesma política intervencionista, como já analisado por André Cavaller Guzzi (2008, p. 32)

As mesmas instituições que antes eram usadas para combater
internacionalmente a expansão do comunismo, passaram a ser destinadas à
eliminação do tráfico de drogas. Dessa forma, é possível dizer que, apesar do
discurso sobre defesa ter se alterado após a Guerra Fria, ou seja, do combate
ao comunismo para o combate ao tráfico de drogas; as políticas de defesa dos
EUA continuaram sendo as mesmas, pois continuou sendo utilizada a mesma
lógica de intervencionismo e militarização em países estrangeiros para buscar
eliminar uma determinada ameaça.

De modo progressivo foi sendo construído um ideal responsável por correlacionar as drogas como uma ameaça existência. Quando o objeto deixa de justificar e fazer parte das políticas internas norte-americanas e passa a afetar outros países do mundo, ou seja, quando a guerra às drogas deixe de ser alvo de política interna para também ser alvo de política externa, num movimento de sistematização daquele objeto, observa-se então um processo de Macrossecuritização (VILLA, 2014).

A macrossecuritização diz respeito a objetos referentes ao nível sistêmico, como ideologias ou religiões universais, instituições primárias de segurança internacional ou doutrinas como a guerra global ao terror, que são capazes de incorporar e coordenar múltiplos níveis mais baixos de securitização. A macrossecuritização opera com a mesma lógica da securititização: uma ameaça existencial a um objeto referente, o que justifica o apelo para as medidas extraordinárias (Villa, 2014, p. 351)

Constata-se, paulatinamente, a produção de políticas internas e sua consequente reprodução por todo o mundo, em um processo de internacionalização de um tema que torna-se matéria e produto, onde os Estados Unidos podem agora exportar e, consequentemente, manter sua influência sobre outros países, em uma produção estrategicamente construída de um processo que agora é macrossecuritizado e torna-se objeto de preocupação não só de um único ator, mas de todo um sistema.

\section{A Guerra às Drogas como objeto de intervenção social e política}

Para um melhor entendimento acerca das consequências sociais envolvidas na crescente regulamentação e proibicionismo da questão das drogas, faz-se importante uma breve análise do conceito de Biopolítica, como trabalhado por Foucault, de modo a CSOnline - Revista Eletrônica de Ciências Sociais, Juiz de Fora, n. 25 (2017), pp. 1-296. 
estabelecer uma compreensão mais profunda dos efeitos de tais legislações sobre a população e, principalmente, sobre determinados grupos sociais.

Segundo o filósofo, o grande afluxo de pessoas para centros urbanos, causado pela indústria capitalista contemporânea, tornou-se um objeto ameaçador para a ordem sociopolítica e econômica, já que dificultava ainda mais a gestão do espaço e a contenção de revoltas e subversões (FOUCAULT, 2008 apud RODRIGUES, 2012). Como consequência, para administrar essa população, se desenvolveu em certos países políticas de medicina social com o intuito justamente de facilitar o gerenciamento não somente o campo social, mas também o espacial que o circunda.

Dentre os motivos responsáveis para que tenha havido uma mudança radical da interpretação no que tange às drogas, pode ser identificado um corte xenófobo e racista feito por interesse dos próprios Estados, visando uma repressão sobre imigrantes ou minorias étnicas. A busca por gerenciar tanto o espacial quanto o social culminou em uma associação de substâncias com determinados grupos sociais, sendo este fator um potencializante da aversão da população a estas substâncias. Desta forma, foi possível introjetar inconscientemente uma relação de determinados grupos sociais e étnicos com certas substâncias ilícitas, o que tornava mais fácil uma crescente proibição que surtiria duplo efeito.

Nos Estados Unidos, por exemplo, foi possível observar uma crescente associação da maconha com hispânicos e hippies, do ópio com chineses e da cocaína e heroína com negros. Já no Brasil, por exemplo, a heroína passou a ser tida como droga de cafetões e prostitutas, enquanto a maconha era tida como substância de negros (RODRIGUES, 2012). Estas associações internalizam na população uma correlação direta entre estas substâncias e os grupos sociais em questão, o que aumenta a repressão a ambos.

Tais associações não necessariamente eram feitas de modo não-intencional, mas podem ser realizadas voluntariamente pelo próprio governo para uma maior repressão daqueles associados. De acordo com John D. Ehrlichman, assessor do ex-presidente Richard Nixon, a campanha presidencial tinha a população negra como inimigos; ao se fazer então uma associação entre negros e uma determinada substância ilícita, a securitização de um teria efeitos direto sobre a insegurança de outro.

The Nixon campaign in 1968, and the Nixon White House after that, had two enemies: the antiwar left and black people. You understand what I'm saying? We knew we couldn't make it illegal to be either against the war or black, but by getting the public to associate the hippies with marijuana and blacks with heroin, and then criminalizing both heavily, we could disrupt those communities. We could arrest their leaders, raid their homes, break up their meetings, and vilify them night after night on the evening news. Did we know

CSOnline - Revista Eletrônica de Ciências Sociais, Juiz de Fora, n. 25 (2017), pp. 1-296. 
we were lying about the drugs? Of course we did. (EHRLICHMAN, 1994 apud LOBIANCO 2016) ${ }^{4}$

Entretanto, tais substâncias não se aplicavam exclusivamente aquele grupo social ao qual estava sendo relacionada; embora a campanha do presidente Nixon tivesse os negros como inimigo declarado, estes, obviamente não eram os únicos consumidores de drogas. A questão cresceu de modo que passou a fazer parte da sociedade como um todo, o consumo ia muito além de negros, porto-riquenhos, mexicanos, pobres e/ou delinquentes, mas também fazia parte dos grupos de jovens brancos da classe média norte-americana. (DEL OLMO, 1990). Todos estes grupos, no entanto, não eram classificados da mesma maneira.

Se a Guerra às Drogas serve, entre outros, para criminalizar determinados grupos sociais em detrimento de outros e as drogas é uma questão que afeta a sociedade como um todo, não fazendo distinção de gênero, raça ou cor, como fazer com que certos grupos sejam socialmente combatidos enquanto outros são absolvidos? Tal questão pode ser entendida através do duplo discurso médico-jurídico que a envolve (DEL OLMO, 1990). O discurso jurídico é aquele que enfatiza o estereótipo de criminoso, determina suas responsabilidades e as consequentes sanções por elas; coloca-se aqueles grupos vítimas de repressão como sendo os responsáveis pela comercialização, o que torna mais fácil qualificá-lo como "delinquente". O consumidor, por sua vez, seria aquele que teria condição social distinta, não se encaixa nos estereótipos a serem combatidos. A partir daí, então, pode ser classificado não como criminoso, mas como "doente", parte do discurso médico difundido.

A partir da promoção da guerra às drogas e de discursos muito bem construídos responsáveis por classificar o "criminoso" e a "vítima", o "bem" e o "mal”, organiza-se uma profunda repressão não somente às drogas, mas também àqueles grupos associados, o que gera graves consequências também na opinião da população. Em 1985, em pesquisa realizada nos Estados Unidos para saber qual era o maior problema da nação, $23 \%$ dos participantes acreditava ser as armas nucleares, enquanto somente $1 \%$ citou as drogas (CAMPBELL, 1992).

Quatro anos depois, em 1989, o então presidente George Bush foi a público para um discurso nacional que estabeleceria as estratégias de seu governo para o controle de drogas. O presidente iniciou dizendo que "todos nós concordamos que o maior problema doméstico que nossa nação enfrenta atualmente é as drogas", e prosseguiu manifestando

\footnotetext{
${ }^{4}$ Disponível em: http://edition.cnn.com/2016/03/23/politics/john-ehrlichman-richard-nixon-drug-war-blacks-hippie/ CSOnline - Revista Eletrônica de Ciências Sociais, Juiz de Fora, n. 25 (2017), pp. 1-296.
} 
sobre como as drogas prejudicam a fé no sistema de justiça e faz com que as cortes prisões fiquem superlotadas (BUSH, 1989).

Após os discursos proferidos por Bush, uma nova pesquisa foi responsável por mostrar uma mudança da percepção daquilo que era responsável por afetar a segurança nacional; agora, o ínfimo número de 1\%, havia passado para $54 \%$ em um período de apenas 4 anos (CAMPBELL, 1992). Tais números chamam a atenção para a influência que os discursos políticos começaram a ter sobre a perspectiva da população. Se há poucas décadas a questão das drogas poderia passar despercebida, hoje é motivo de grande repressão social incontestável na mentalidade de grande parte das pessoas, visto que, paulatinamente, foi-se construindo uma correlação das drogas com certos grupos sociais, assim como causadora de violência, o que legitima socialmente as medidas que viriam a ser tomadas para sua contenção.

Estes discursos, entretanto, não ficaram no passado; ao contrário, se propagam diariamente e se mantêm presente no âmago da população, inclusive líderes políticos, agentes de grande influência sobre a opinião pública. Como exemplo, podem ser citados alguns dos discursos proferidos pelo atual presidente dos Estados Unidos, Donald Trump, que atuam sob uma série de estereótipos irreais, sem qualquer embasamento científico. No último ano, o atual presidente chegou a dizer em entrevista à CBS que "quando o México manda pessoas, eles não estão mandando as melhores. Estão mandando pessoas que possuem uma série de problemas... Eles estão trazendo drogas, trazendo crime, são estupradores" (TRUMP, 2016 apud MILLER, 2016).

A despeito da relação abertamente estabelecida no governo de Richard Nixon com negros e, atualmente, no governo de Trump, com mexicanos, uma pesquisa realizada pela America Public Health Association ao longo de 12 anos (1995-2007) com 1.829 jovens detidos em Chicago entre 1995 e 1998, o número de jovens norte-americanos brancos que eram usuários de drogas foi superior ao número de latinos ou negros. Tais números não são exclusivos do sistema norte-americano.

Ao contrário dos estereótipos comumente propagados, responsáveis por relacionar as drogas a certos grupos sociais, como negros e migrantes, a realidade é díspar e nem sempre condiz com a imagem engendrada. Ainda assim, através de discursos minuciosamente construídos e com alto poder de influência, proferidos por líderes de Estados, além de todo o aparato disponível, como propagandas e legislações proibitivas, cria-se, sobre a população, uma cultura do medo, que agora prevalece e insiste em relacionar, mesmo que de forma inconsciente, a imagem de grupos que devem ser combatidos para que se resolva o problema das drogas.

CSOnline - Revista Eletrônica de Ciências Sociais, Juiz de Fora, n. 25 (2017), pp. 1-296. 
Embora muito tenha sido exposto sobre a produção da Guerra às Drogas pelos Estados Unidos, é importante ressaltar que este é um tema sistêmico que habita o internacional e, propositalmente - ou não, pode e vem sendo utilizado como instrumento de produção de políticas externas e influência norte-americana sobre outros territórios. É possível notar que a partir de todo o discurso maniqueísta produzido em cima da Guerra às Drogas; a adoção de políticas excepcionais permite agora a utilização do narcotráfico também como matéria de influência e exportação de recursos, assim como a consequente legitimação de discursos que ultrapassam as fronteiras norte-americanas.

Simultaneamente ao ocorrido nos Estados Unidos, na década de 1970 se observa a regulação de um discurso jurídico em toda a América Latina e a importação de discursos de pânico e terror atribuídos aos estereótipos das drogas (DEL OLMO, 1990). Tais estereótipos muitas das vezes não eram condizentes com a realidade de determinada substância a qual estava sendo atribuído, mas é muito significativo para se observar toda a influência produzida pelos EUA que fazia com que países importassem um discurso sem questioná-lo ou saber do que realmente se tratava.

Difundiu-se na época uma série de informações que tinham a ver com a heroína nos Estados Unidos, mas que alguns "especialistas" da América Latina relacionavam com "a droga" em geral de maneira bastante irresponsável. Os resultados foram desastrosos porque estavam sendo importados, e sendo impostos, discursos alheios que não levavam em conta nem a diferença entre as drogas, nem entre os grupos sociais. (DEL OLMO, 1990, p. 46)

A naturalização e importação dos discursos de guerra às drogas por parte de países latino-americanos se insere em dado momento contextual onde se observa um crescente problema com estas drogas. Tratar então de um inimigo estigmatizado e envolto em incertezas e informações incorretas, mas responsável por gerar tamanho terror, permite e de certa forma facilita a intervenção norte-americana em assuntos internos e na produção de políticas dos países em questão.

Toda a popularização da ideia das drogas como sendo uma ameaça à segurança nacional, levou o presidente Reagan a assinar em abril de 1986 uma ordem secreta que autorizava o uso de forças militares nas Américas Central e do Sul (CAMPBELL, 1992). Tal ato é responsável por dar um caráter ainda mais ofensivo à política externa no que tange a questão da guerra às drogas, ratificando a ideia, como trabalhada por Rafael Duarte Villa (2014) deste ter se tornado um objeto de atuação não mais único, mas sistêmico. Com a justificativa de combater o tráfico de drogas, então, foi permitido um maior intervencionismo e militarização sobre países da América, o que é responsável por múltiplas consequências. 
Consequentemente, há um aumento dos gastos que se reflete num aumento da militarização não só nos Estados Unidos, mas também de todo o continente americano com o intuito de se fazer um combate às drogas. No período de 2000 a 2005, por exemplo, os EUA destinaram mais de R \$4 bilhões para assistência militar na América Latina. ${ }^{5}$

A Colômbia foi o principal foco norte-americano; em 2000 houve a criação do Plano Colômbia, elaborado em conjunto pelos governos de ambos os países. O Plano tem como objetivo por parte da Colômbia o reestabelecimento da ordem e da segurança no Estado, enquanto os EUA têm como seu objetivo primário a prevenção do fluxo de drogas ilegais para seu território (VEILLETTE, 2005).

Embora possua certos êxitos, alguns dos resultados mostram que, mesmo aumentando a erradicação no cultivo de drogas, a disponibilidade e o preço da cocaína e da heroína nos Estados Unidos continuaram estáveis (VEILLETTE, 2005). Além disso, muitos pesquisadores concordam que o tráfico de drogas não diminuiu e as consequências acabaram sendo negativas, como apresentado por Oliveira (2006):

Desde meados do ano 2000, quando o governo dos Estados Unidos aprovou o
Plano Colômbia - um amplo programa de ajuda militar, totalizando mais de
US\$ 1,3 bilhão, a maior parte dele destinada ao exército colombiano, apesar
de seu péssimo histórico em matéria de direitos humanos e da contínua
preocupação internacional sobre os vínculos entre as forças de segurança e os
grupos paramilitares -, os conflitos armados se acirraram e o fenômeno
migratório desse país vem tomando dimensões alarmantes.

Uma das consequências de toda a guerra às drogas na Colômbia pode ser observada através do desplaziamento (um termo sem terminologia equivalente em português), onde os desplazados vivem em fuga na tentativa de escapar da morte e das ameaças constantes em territórios dominados pelos narcotraficantes, mas se encaixam em uma categoria peculiar de migrantes a partir do momento que continuam na categoria de provisório devido ao desejo de regressar à Colômbia (OLIVEIRA, 2006).

Tem-se então uma internacionalização do conflito colombiano frente ao Plano Colômbia, assim como da guerra às drogas. Então, embora o citado plano possua seus resultados positivos, se faz importante também para uma maior consistência da questão, uma observação da responsabilidade do Plano Colômbia sobre a produção de uma violência sistêmica e de problemas tanto internos, quanto externos.

Além da Colômbia, caso exemplar da intervenção norte-americana na América Latina no que diz respeito a guerra às drogas, também houve o investimento em outros países da América do Sul e Central para, por exemplo, a construção de bases militares, conhecidas como Locais de Segurança Cooperativa (Cooperative Security Locations -

\footnotetext{
${ }^{5}$ Dados disponíveis em: http://repositorio.unesp.br/bitstream/handle/11449/96289/guzzi_ac_me_mar.pdf?sequence=1 CSOnline - Revista Eletrônica de Ciências Sociais, Juiz de Fora, n. 25 (2017), pp. 1-296.
} 
CSL) e também a instalação de radares e militares para fiscalizar e deter ações de traficantes de drogas em países como Brasil, Peru, Colômbia e Equador (GUZZI, 2008)

Tais medidas, incentivadas pelos Estados Unidos na exportação da guerra às drogas, podem ser vistas também como uma forma de intervenção do país na América Latina. É através destes programas e da contribuição de recursos financeiros e militares dispostos pelo país norte-americano que se tem garantida uma zona de influência em outros Estados, assim como é possível se fazer presente em seus respectivos territórios através do argumento de contenção do tráfico de drogas.

A chamada guerra às drogas, assim como sua consequente macrossecuritização, foi paulatinamente sendo construída pelos Estados Unidos através de discursos e políticas que, com o passar do tempo, deixaram de ser exclusivas ao território norte-americano, para habitarem um nível sistêmico. Tais políticas agora se estendem em perspectivas micro e macro, tanto políticas quanto sociais. Em uma perspectiva micro, observa-se a guerra às drogas como instrumento de influência social, que afeta a todos individualmente, seja a partir da repressão direta de certos grupos sociais, ou com a introjeção da cultura do medo. Em um campo de análise macro, pode ser observada a influência também em um nível internacional, através da produção de políticas externas que serve como instrumento de intervenção norte-americana e permite a presença do país em outros territórios para a manutenção de sua própria hegemonia.

\section{Conclusão}

Dado o que aqui foi exposto em texto, entende-se que se faz necessária uma nova forma de lidar com a questão do narcotráfico. A guerra às drogas se iniciou há cerca de 50 anos e, no atual modelo de repressão, vem sendo responsável por produzir consequências que são prejudiciais em diversos níveis e setores sociais.

A securitização do tema e a apresentação deste como uma ameaça existencial aos Estados Unidos, faz parte de uma política xenofóbica e racista, responsável por perseguir determinados grupos e minorias étnicas e sociais. Esta consequente insegurança causada para estes grupos, pôde ser observada através da análise de discursos de líderes políticos que se colocavam com o objetivo de reprimir não somente a utilização, comercialização e o tráfico de drogas, mas também determinados e convenientes grupos sociais e étnicos.

Através da assimilação estabelecida entre certas substâncias com determinados grupos sociais, como no caso de Trump com os migrantes mexicanos, ou de Nixon com os negros, faz-se possível uma repressão não só das drogas, mas também destes grupos CSOnline - Revista Eletrônica de Ciências Sociais, Juiz de Fora, n. 25 (2017), pp. 1-296. 
em questão. Tais políticas são diretamente responsáveis pela produção de medo no imaginário social, que automaticamente passa a personificar um inimigo, o que é responsável também por intensificar o racismo e a xenofobia.

A apresentação destas políticas como sendo necessárias para acabar com a suposta ameaça nacional que o narcotráfico representa, é responsável por criar estigmas que se tornam característicos na opinião pública, que fica impossibilitada de fazer uma análise mais objetiva do quão decadentes e nocivas são as políticas de guerra às drogas.

Além disso, a guerra às drogas foi e vem sendo prejudicial não somente para a política interna norte-americana, mas também no tratamento da política externa, na produção e disseminação do medo e de políticas intervencionistas responsáveis por consequências nocivas que ultrapassam as fronteiras nacionais e chegam em toda a América Latina.

É importante ressaltar que a Guerra às Drogas ainda é tema muito presente em discussões, na produção de políticas e, consequentemente, na produção de conhecimento. Por afetar de forma tão incisiva a sociedade em diversos níveis, desde um âmbito pessoal até o internacional, este artigo não se apresenta como um trabalho que aqui se finda. Como o atual modelo de proibição e repressão das drogas se modifica a todo instante, através de atores de repressão e resistência, sua consequente produção de políticas também sofre constantes reformas responsáveis por afligir diretamente os sujeitos e suas formas.

\section{Referências}

BRASIL. Decreto $n^{\circ}$ 2.994, de 17 de agosto de 1938. Promulga a Convenção para a repressão do tráfico ilícito das drogas nocivas. Disponível em:

http://www.oas.org/juridico/MLA/pt/bra/pt_bra_1936_convencao_repressao_trafico.pdf BUZAN, Barry; WAEVER, Ole; WILDE, Jaap de. Security: A New Framework For Analysis. Boulder: Lynne Rienner Publishers, 1998.

BIGO, Didier. International Political Sociology. In: Williams, Paul (ed.). Security

Studies: An Introduction. Nova York: Routledge, 2008.

Campbell, David. Writing Security: United States Foreign Policy and the Politics of Identity, Rev. Ed. Minneapolis: University of Minnesota Press, 1992.

DEL OLMO, Rosa. A face oculta da droga. Rio de Janeiro: REVAN, 1990.

GUZZI, A. As relações EUA-América Latina: medidas e consequências da política externa norte-americana para combater a produção e o tráfico de drogas ilícitas.

2008. 130 f. Dissertação (Mestrado em Relações Internacionais) - UNESP, UNICAMP, PUC/SP, São Paulo, 2008.

CSOnline - Revista Eletrônica de Ciências Sociais, Juiz de Fora, n. 25 (2017), pp. 1-296. 
H. W. Bush, G. President's Speech on National Drug Control Strategy. Washington D.C.: White House, 5 set. 1989. Discurso realizado pelo presidente George H. W. Bush na Casa Branca. Disponível em: <http://www.nytimes.com/1989/09/06/us/text-ofpresident-s-speech-on-national-drug-control-strategy.html?pagewanted=all>

LoBianco, T. Report: Nixon's war on drugs targeted black people. Disponível em: <http://edition.cnn.com/2016/03/23/politics/john-ehrlichman-richard-nixon-drug-warblacks-hippie/>. Acesso em: jun. 2016.

MILLER, Jake. Donald Trump defends calling Mexican immigrants "rapists". Disponível em: <http://www.cbsnews.com/news/election-2016-donald-trump-defendscalling-mexican-immigrants-rapists/> . Acesso em: 06 jun. 2017.

NIXON, Richard. Remarks About an Intensified Program for Drug Abuse Prevention and Control. Washington D.C.: White House, 17 jun. 1971. Discurso realizado pelo presidente Nixon na Casa Branca. Disponível em: < http://www.presidency.ucsb.edu/ws/?pid=3047>

OLIVEIRA, M. A mobilidade humana na tríplice fronteira: Peru, Brasil e Colômbia. Estudos Avançados. São Paulo, v.20, n.57, 2006. Disponível em: <http://www.scielo.br/scielo.php?script=sciarttext\&pid=S0103-40142006000200014>. Acesso em: jun. 2016.

THORNTON, Mark. Cato Institute Policy Analysis No. 157: Alcohol Prohibition Was a Failure. Disponível em: <Cato Institute Policy Analysis No. 157: Alcohol Prohibition Was a Failure>. Acesso em: jun. 2017.

VILLA, Rafael Duarte. O Paradoxo da Macrossecuritização: Quando a Guerra ao Terror não Securitiza Outras "Guerras” na América do Sul. Contexto Internacional, vol. 36, n. 2, jul-dez. 2014, pp. $349-383$.

VEILlETE, Connie. Plan Colombia: A Progress Report. (GAO-10-837). CRS Report for Congress No. RL 32774. Washington, DC.: Congressional Research Service, Jun. 22, 2005.

WELTY, Leah J. et al. Health Disparities in Drug- and Alcohol-Use Disorders: A 12-Year Longitudinal Study of Youths After Detention. American Journal Of

Public Health, [s.1.], v. 106, n. 5, p.872-880, maio 2016. American Public Health Association. http://dx.doi.org/10.2105/ajph.2015.303032.

RODRIGUES, Thiago. Narcotráfico e Militarização nas Américas: Vício de Guerra. Contexto Internacional, Rio de Janeiro, v. 34, n. 1, p.9-41, jun. 2012. Semestral. 